Document downloaded from:

http://hdl.handle.net/10251/169028

This paper must be cited as:

Esteso, A.; Alemany Díaz, MDM.; Ortiz Bas, A.; Zaraté, P. (2020). Optimization Models to Improve First Quality Agricultural Production through a Collaboration Program in Different Scenarios. IFIP Advances in Information and Communication Technology. 598:546-559. https://doi.org/10.1007/978-3-030-62412-5_45

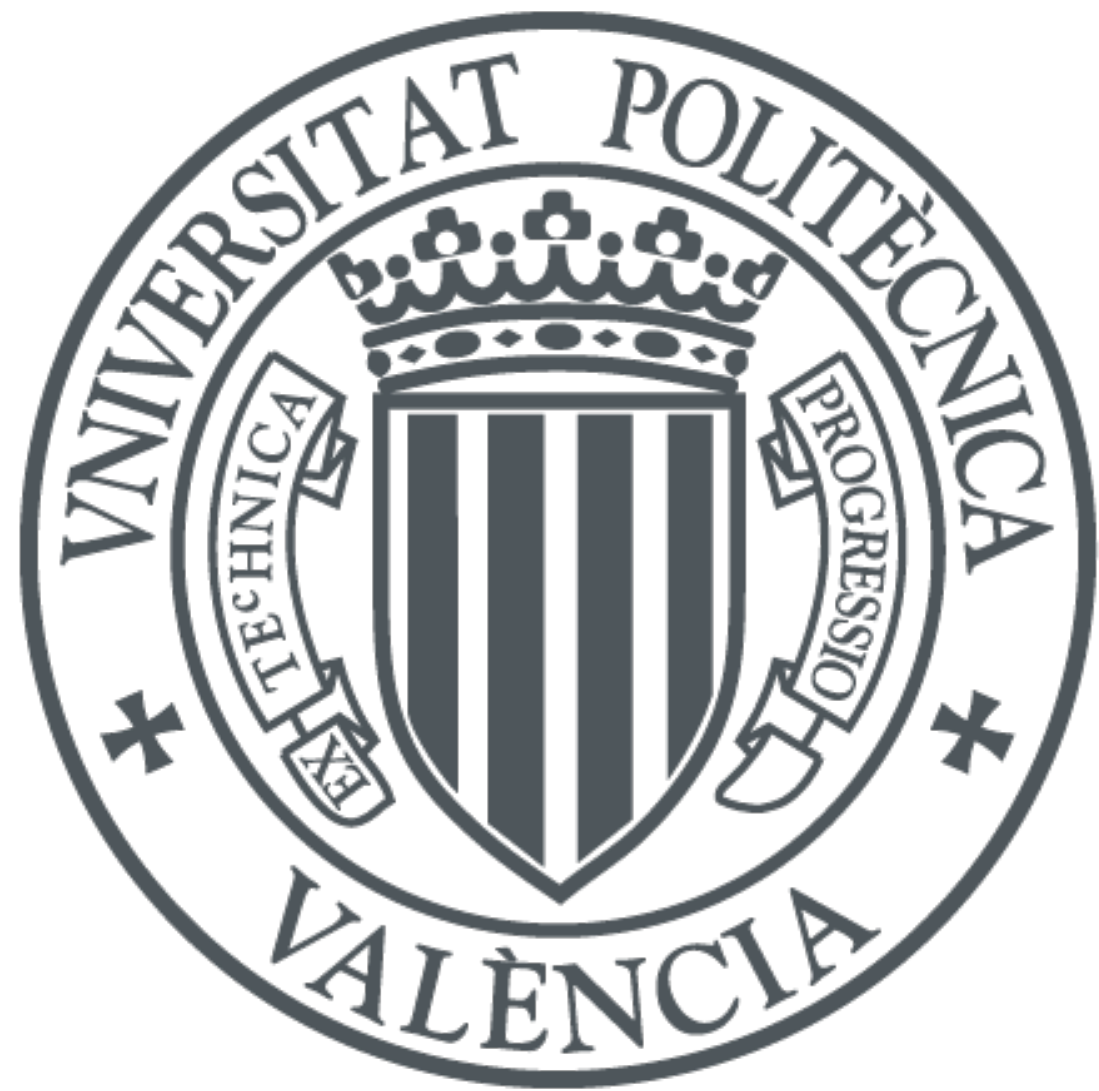

The final publication is available at

https://doi.org/10.1007/978-3-030-62412-5_45

Copyright Springer

Additional Information 


\title{
Optimization Models to Improve First Quality Agricultural Production through a Collaboration Program in different Scenarios
}

\author{
Ana Esteso ${ }^{1}$, MME Alemany ${ }^{1}$, Ángel Ortiz ${ }^{1}$, and Pascale Zaraté2 \\ ${ }^{1}$ Research Centre on Production Management and Engineering (CIGIP). Universitat \\ Politècnica de València. Camino de Vera S/N, 46022 València, Spain; \\ ${ }^{2}$ IRIT, Toulouse University, Toulouse, France \\ \{aesteso,mareva, aortiz\}@cigip.uvp.es, zarate@irit.fr
}

\begin{abstract}
Consumers increasingly require products with higher qualities, leading to loss units not meeting these requirements. Collaboration can be used to increase first quality products production and reduce waste generated along the chain. A collaboration program consisting in a system of investments made by retailers to cooperatives to improve the skills of farms is proposed for this aim. The novelty of this paper is threefold: 1 ) the business model considered in which cooperatives distribute funds among farms, 2) the inclusion of the dynamic state of products, modelling the quality variation timewise, and 3) the mathematical modelling of five scenarios with different criteria for allocating funds to farms. Results are analyzed and compared for the three aspects of sustainability concluding that: 1) the collaboration program increases the quality of products sold, and 2) interesting tradeoffs occur among the sustainability dimensions, enabling the reduction of unfairness among farms by slightly worsening economic aspects.
\end{abstract}

Keywords: Agri-Food; Collaboration; Quality; Unfairness; Optimization.

\section{Introduction}

Society is increasingly requiring products with higher qualities, what leads to the waste of products not reaching the required quality. At present, this entails wasting one third of the global harvest [1]. According to the FAO [2], these waste have to be reduced by $60 \%$ by 2050 to ensure the sustainability of the agri-food sector.

As a solution, different authors [3-9] implement a collaboration program (CP) among the members of agricultural supply chains to increase the proportion of high quality products to be obtained from the same land. This CP consists in a system of investments made by retailers to small farms (less than 2 ha) that allows them to acquire new technologies, machineries and/or training [3]. It is remarkable that research on agrifood supply chain collaboration particularly focusing on small-scale farmers is in its early development $[10,11]$. The main characteristics of the $\mathrm{CP}$ contemplated in these studies are displayed in Table 1, in which CP proposed in this paper is also characterized to establish its differences from existing literature.

The analyzed papers [3-9] do not take into account the cooperatives in the CP. However, a cooperative is an aggrupation of farms that assists its members to facilitate the commercialization of products and provide them resources for the improvement of products [9]. Therefore, it makes sense to think that cooperatives should be responsible 
Model to Improve $1^{\text {st }}$ Quality Agricultural Production through Collaboration Program 2

of distributing investments made by retailers among their members. On the other hand, analyzed CP decided how to distribute funds among farmers only attending to economic reasons. However, when centrally optimize the entire SC profits leads to inequalities in the profits obtained by the SC members, creating an unfairness concern among them [12] and the unwillingness to collaborate in the implementation of decisions [13].

Table 1. Literature review

\begin{tabular}{|c|c|c|c|c|c|c|c|c|}
\hline \multirow[t]{2}{*}{ Reference } & \multicolumn{3}{|c|}{$\mathrm{CP}$ participants } & \multicolumn{2}{|c|}{$\begin{array}{l}\text { Type of funding } \\
\text { distribution }\end{array}$} & \multicolumn{3}{|c|}{$\begin{array}{l}\text { Main criteria for } \\
\text { funding distribution }\end{array}$} \\
\hline & $\mathrm{F}$ & $\mathrm{C}$ & MR & $\mathrm{S}$ & M & SCP & UFD & UID \\
\hline Esteso et al. [3] & $\mathrm{X}$ & & $\mathrm{X}$ & $\mathrm{X}$ & & $\mathrm{X}$ & & \\
\hline Sutopo et al. [4] & $\mathrm{X}$ & & $\mathrm{X}$ & $\mathrm{X}$ & & $\mathrm{X}$ & & \\
\hline Sutopo et al. [5] & $\mathrm{X}$ & & $X$ & $\mathrm{X}$ & & $\mathrm{X}$ & & \\
\hline Sutopo et al. [6] & $\mathrm{X}$ & & $\mathrm{X}$ & $\mathrm{X}$ & & $\mathrm{X}$ & & \\
\hline Sutopo et al. [7] & $\mathrm{X}$ & & $\mathrm{X}$ & $\mathrm{X}$ & & $\mathrm{X}$ & & \\
\hline Sutopo et al. [8] & $\mathrm{X}$ & & $\mathrm{X}$ & $\mathrm{X}$ & & $\mathrm{X}$ & & \\
\hline Wahyudin et al. [9] & $\mathrm{X}$ & & $\mathrm{X}$ & $\mathrm{X}$ & & $\mathrm{X}$ & & \\
\hline This paper & $\mathrm{X}$ & $\mathrm{X}$ & $\mathrm{X}$ & $X$ & $X$ & $\mathrm{X}$ & $\mathrm{X}$ & $X$ \\
\hline
\end{tabular}

F: Small farm, C: Cooperative, MR: Modern retailer, S: Single criteria, M: Multiple criteria; SCP: Supply chain profits, UFD: Unfairness in funds distribution, UIC: Unfairness in incomes distribution

To fill this gap in literature, this paper adapts the model proposed in [3] to this new business model. In this novel environment, it is necessary to consider the cooperative role when selecting possible ways of distributing funds among farms, what defines different collaboration scenarios. Collaboration arises from the agreements and trust mechanisms accepted and adopted by members from a SC [14]. Collaboration plays an important role in this problem since decisions are made in a synchronized way to obtain better solutions for the entire supply chain (SC) and an incentive alignment is made by distributing the investments among farms [15]. Five different mathematical models are developed for each collaboration scenario. Besides, all models include the transformation of $1^{\text {st }}$ quality product into $2^{\text {nd }}$ quality over time due to the perishability of the agricultural products.

The rest of the paper is structured as follows. Section 2 describes the problem under study and the collaboration scenarios identified in the agri-food sector. Section 3 presents the MILP models developed for the defined scenarios. Section 4 implements the models and evaluate the solutions for different indicators related to the triple bottom line. Finally, Section 5 outlines conclusions and future research lines.

\section{Problem and Collaboration Scenarios Description}

The SC under study commercializes vegetables with limited shelf-life. It is composed by small farms, cooperatives, modern retailers, and consumer markets. Small farms are responsible for the cultivating and harvest of vegetables, their classification into $1^{\text {st }}$ and $2^{\text {nd }}$ quality products and their transport to cooperatives. Cooperatives transport $1^{\text {st }}$ 
Model to Improve $1^{\text {st }}$ Quality Agricultural Production through Collaboration Program 3

quality products to retailers who commercialize them to consumer markets, and $2^{\text {nd }}$ quality product directly to consumer markets where are sold at a very low price. Due to the perishability of vegetables, $1^{\text {st }}$ quality products become $2^{\text {nd }}$ quality products if they are not sold in the same period of their harvest. In addition, $2^{\text {nd }}$ quality products become uneatable from one period to the next, what leads to the waste of unsold units.

A CP is implemented to increase the quantity of $1^{\text {st }}$ quality products to be obtained from harvest and to reduce the waste generated along the chain. It consists on a system of investments made by retailers to cooperatives, who share the collected investments among the farm members. The CP defines three farming skill levels related to the proportion of $1^{\text {st }}$ quality product obtained from harvest. Each fund allows farms to improve the $1^{\text {st }}$ quality proportion and move up from one skill level to another. The budget for the $\mathrm{CP}$ is limited as well as the number of funds that each farm can receive. Different scenarios for the distribution of funds among farms are analyzed (Fig. 1).

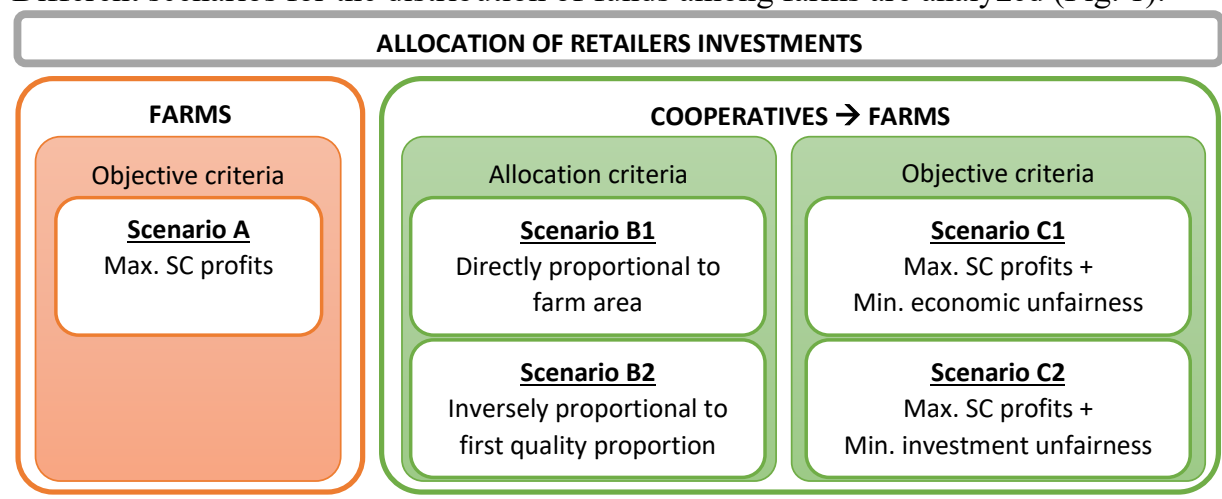

Fig. 1. Scenarios for funding allocation

In Scenario A retailers directly invest on those farms that maximize the SC profits such as in [3]. In the rest of scenarios, retailers invest in cooperatives that share funds among their members. In Scenarios B, cooperatives distribute the funds according to a fixed allocation criterion while in Scenarios $\mathrm{C}$, cooperatives allocate the funds to farms by optimizing two SC objectives. More specifically, in Scenario B1, cooperatives distribute the funds in a way proportional to the farms area (biggest farms obtain more funds) while in Scenario B2, cooperatives distribute the funds in an inversely proportional way to the mean $1^{\text {st }}$ quality proportion of farms (farms with lower proportion of $1^{\text {st }}$ quality product would receive more funds). In case of Scenario C1, cooperatives allocate the funds to farms by maximizing the SC profits and minimizing the unfairness in the incomes received by farms. Finally, in Scenario C2, the funds distribution is made by maximizing the SC profits and minimizing the unfairness in the distribution of funds among farms. One MILP model is proposed for each of the Scenarios. It is noteworthy that the resulting MILP models for the scenarios C1 and C2 are multi-objective. 
Model to Improve $1^{\text {st }}$ Quality Agricultural Production through Collaboration Program 4

\section{Mathematical Programming Models Formulation}

The nomenclature employed to formulate the MILP models aligned to the proposed scenarios is exposed in Table 2, where $v$ refers to vegetables, $c$ to the quality of vegetables, $i$ to small farms, $j$ to cooperatives, $k$ to modern retailers, $m$ to consumer markets, $t$ to the period of time, $F C_{i}$ to the set of small farms that belong to the cooperative $j$, and $I J_{j}$ to the cooperative to which farm $i$ belongs.

Table 2. Nomenclature

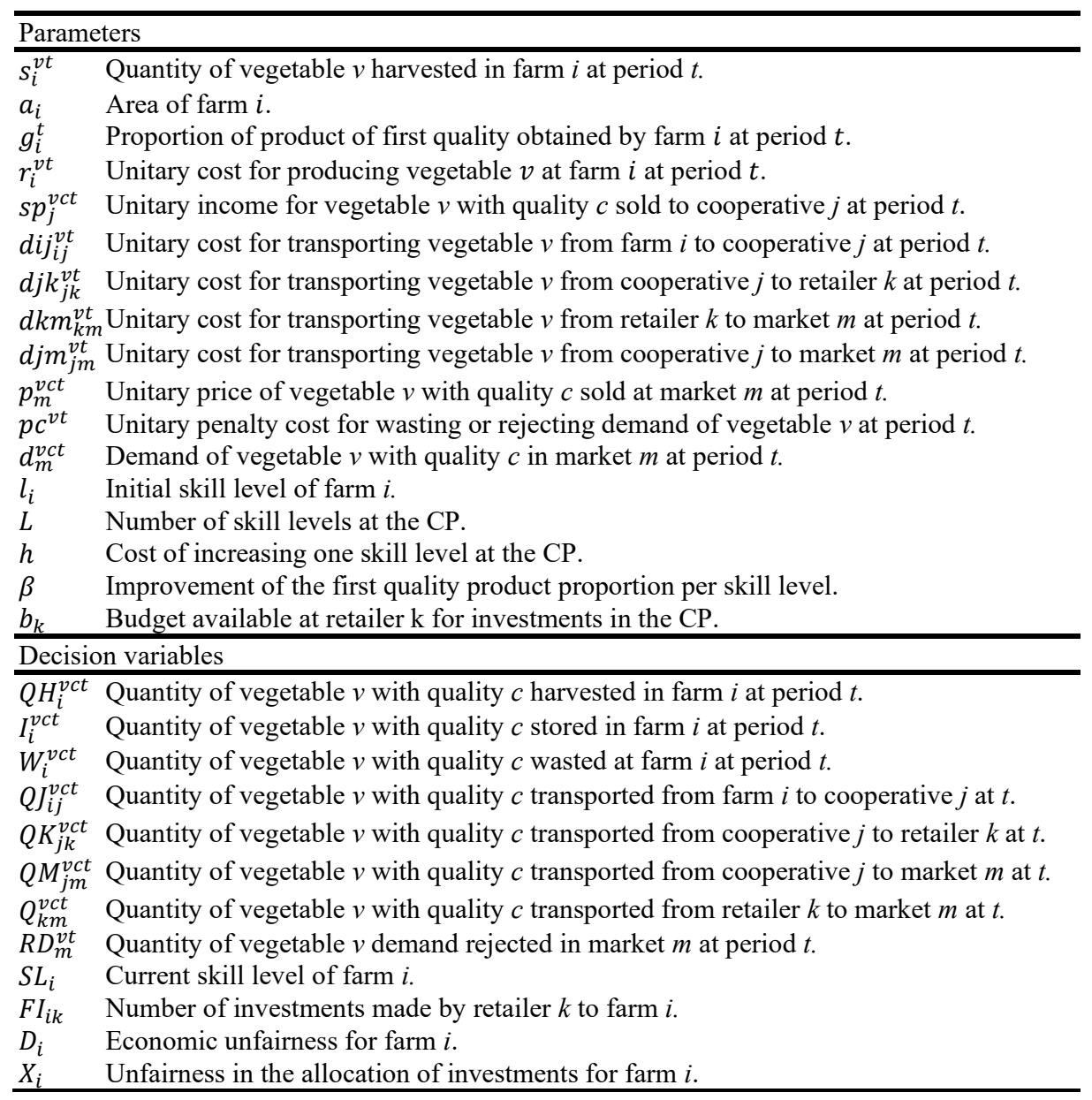


Model to Improve $1^{\text {st }}$ Quality Agricultural Production through Collaboration Program 5

\subsection{Scenario A: Direct Investments to Farms}

This model, based on [3], is adapted to introduce the demand dependent on qualities and the evolution of qualities with time. It maximizes the SC profits composed by the incomes per sales of vegetables, production and transport costs, penalty costs related to waste and unmet demand, and the investments made within the CP (1).

$$
\begin{aligned}
\max Z_{A}=\sum_{v} \sum_{c} \sum_{t} & \left(\sum_{k} \sum_{m} Q_{k m}^{v c t} \cdot p_{m}^{v c t}+\sum_{j} \sum_{m} Q M_{j m}^{v c t} \cdot p_{m}^{v c t}-\sum_{i} Q H_{i}^{v c t} \cdot r_{i}^{v c t}\right. \\
& -\sum_{i} \sum_{j \in F C_{i}} Q J_{i j}^{v c t} \cdot d i j_{i j}^{v t}-\sum_{j} \sum_{k} Q K_{j k}^{v c t} \cdot d j k_{j k}^{v t} \\
& -\sum_{j} \sum_{m} Q M_{j m}^{v c t} \cdot d j m_{j m}^{v t}-\sum_{k} \sum_{m} Q_{k m}^{v c t} \cdot d k m_{k m}^{v t} \\
& \left.-\sum_{i} W_{i}^{v c t} \cdot p c^{v t}-\sum_{m} R D_{m}^{v c t} \cdot p c^{v t}\right)-\sum_{i} \sum_{k} F_{i k} \cdot h
\end{aligned}
$$

The model is subjected to the following constraints. All product ready for harvest in one period is harvested by farmers (2) and classified into $1^{\text {st }}$ quality and $2^{\text {nd }}$ quality products.

$$
s_{i}^{v t}=\sum_{c} Q H_{i}^{v c t} \quad \forall v, t, i
$$

To determine the quantity of $1^{\text {st }}$ quality products, the total quantity to be harvested is multiplied by the initial proportion of $1^{\text {st }}$ quality products at the farm in this period plus the improvement of such proportion thanks to the $\mathrm{CP}(3)$. The rest of harvested product is classified as $2^{\text {nd }}$ quality products (4).

$$
\begin{array}{ll}
Q H_{i}^{v c t}=s_{i}^{v t} \cdot\left(g_{i}^{t}+\beta \cdot S L_{i}\right) & \forall v, c=1, t, i \\
Q H_{i}^{v c t}=s_{i}^{v t} \cdot\left(1-g_{i}^{t}-\beta \cdot S L_{i}\right) & \forall v, c=2, t, i
\end{array}
$$

Once harvested, the $1^{\text {st }}$ quality product can be transported to the cooperative, stored at the farming location until the following period, or wasted (5). In case a $1^{\text {st }}$ quality product is stored, it is transformed into $2^{\text {nd }}$ quality product in the following period (6).

$$
\begin{array}{ll}
Q H_{i}^{v c t}=\sum_{j \in F C_{i}} Q J_{i j}^{v c t}+W_{i}^{v c t}+I_{i}^{v c t} & \forall v, c=1, t, i \\
I_{i}^{v 1 t}=I_{i}^{v 2 t+1} & \forall v, t, i
\end{array}
$$

On the other hand, the $2^{\text {nd }}$ quality product harvested, and the $2^{\text {nd }}$ quality product originated from $1^{\text {st }}$ quality product transformation can be transported to cooperatives or wasted (7). Note that $2^{\text {nd }}$ quality product cannot be stored from one period to the following due to perishability and quality loss reasons.

$$
Q H_{i}^{v c t}+I_{i}^{v c t}=\sum_{j \in F C_{i}} Q J_{i j}^{v c t}+W_{i}^{v c t} \quad \forall v, c=2, t, i
$$

Once $1^{\text {st }}$ and $2^{\text {nd }}$ quality products arrive to the cooperative, $1^{\text {st }}$ quality products are transported to modern retailers (8) while $2^{\text {nd }}$ quality products are directly transported to consumer markets $(10)$. Therefore, it is not allowed to transport $1^{\text {st }}$ quality products from cooperatives to consumer markets $(9)$ and $2^{\text {nd }}$ quality products from cooperatives to modern retailers (11).

$$
\begin{array}{ll}
\sum_{i} Q J_{i j}^{v c t}=\sum_{k} Q K_{j k}^{v c t} & \forall v, c=1, t, j \\
Q M_{j m}^{v c t}=0 & \forall v, c=1, t, j
\end{array}
$$




$$
\begin{array}{ll}
\sum_{i} Q J_{i j}^{v c t}=\sum_{m} Q M_{j m}^{v c t} & \forall v, c=2, t, j \\
Q K_{j k}^{v c t}=0 & \forall v, c=2, t, j
\end{array}
$$

On their part, modern retailers are responsible of transporting the received $1^{\text {st }}$ quality products to the consumer markets (12).

$$
\sum_{j} Q K_{j k}^{v c t}=\sum_{m} Q_{k m}^{v c t} \quad \forall v, c, t, k
$$

Finally, the demand for each product and quality is met at consumer markets. In case there is not enough product to meet the demand, unmet demand is calculated (13).

$$
\sum_{k} Q_{k m}^{v c t}+\sum_{j} Q M_{j m}^{v c t}+R D_{m}^{v c t}=d_{m}^{v c t} \quad \forall v, c, t, m
$$

Regarding the CP, it is ensured that the proportion of first quality product obtained at each farm is lower or equal to the unit (14).

$$
g_{i}^{t}+\beta \cdot S L_{i} \leq 1 \quad \forall i, t
$$

The skill level of each farm is limited by the quantity of skill levels defined in the CP (15). In addition, the skill level of each farm depends on their initial skill level and the number of investments received from retailers, in a way that one received investment switches the farm to the next skill level (16).

$$
\begin{array}{ll}
S L_{i} \leq L & \forall i \\
S L_{i}=l_{i}+\sum_{k} F I_{i k} & \forall i
\end{array}
$$

The quantity of investments made by a retailer is limited by their budget for the CP (17). $\sum_{i} F I_{i k} \cdot h \leq b_{k} \quad \forall k$

Finally, the nature of variables is defined in (18).

$$
\begin{array}{ll}
Q H_{i}^{v c t}, Q J_{i j}^{v c t}, W_{i}^{v c t}, I_{i}^{v c t}, Q K_{j k}^{v c t}, Q M_{j m}^{v c t}, Q k m, R D_{m}^{v c t} & \text { CONTINUOUS } \\
F I_{i k}, S L_{i} & \text { INTEGER }
\end{array}
$$

\subsection{Scenarios B: Investments to Cooperatives - Allocation Criteria}

In Scenarios B, retailers invest on cooperatives that share the funds among their members according to different allocation criteria. Scenario B1 allocates the funds to farms in a proportional way to their areas while Scenario B2 allocated them in an inversely proportional way to the initial proportion of $1^{\text {st }}$ quality production per farm.

The MILP model of Scenario A is adapted to Scenarios B by changing constraints related to the distribution of funds (16-17), and adding two new decision variables: $F J_{j k}$ reflecting the investments made by retailer $k$ to cooperative $j$, and $I n v_{i}$ referring to the number of funds received by farm $i$. Both scenarios pursue the maximization of the SC profits that is reformulated as in equation (19). 


$$
\begin{aligned}
\max Z_{B}=\sum_{v} \sum_{c} \sum_{t} & \left(\sum_{k} \sum_{m} Q_{k m}^{v c t} \cdot p_{m}^{v c t}+\sum_{j} \sum_{m} Q M_{j m}^{v c t} \cdot p_{m}^{v c t}-\sum_{i} Q H_{i}^{v c t} \cdot r_{i}^{v c t}\right. \\
& -\sum_{i} \sum_{j \in F C_{i}} Q J_{i j}^{v c t} \cdot d i j_{i j}^{v t}-\sum_{j} \sum_{k} Q K_{j k}^{v c t} \cdot d j k_{j k}^{v t} \\
& -\sum_{j} \sum_{m} Q M_{j m}^{v c t} \cdot d j m_{j m}^{v t}-\sum_{k} \sum_{m} Q_{k m}^{v c t} \cdot d k m_{k m}^{v t} \\
& \left.-\sum_{i} W_{i}^{v c t} \cdot p c^{v t}-\sum_{m} R D_{m}^{v c t} \cdot p c^{v t}\right)-\sum_{j} \sum_{k} F J_{j k} \cdot h
\end{aligned}
$$

Scenario B1. It allocates funds to farms in a proportional way to the farms' areas (the greater the area, more funds) and is formulated as follows.

$$
\max Z_{B}
$$

Subject to:

$$
\begin{array}{ll}
\sum_{j}^{(2)} F J_{j k} \cdot h \leq b_{k} & \forall k \\
\sum_{k} F J_{j k}=\sum_{i \in I J_{j}} I n v_{i} & \forall j \\
S L_{i}=l_{i}+I n v_{i} & \forall i \\
I n v_{i} \leq \sum_{j \in F C_{i}} \sum_{k} \frac{F J_{j k} \cdot a_{i}}{\sum_{i_{2} \in I J_{j}} a_{i_{2}}}+0.5 & \forall i
\end{array}
$$

$F J_{j k}, \operatorname{Inv} v_{i}$

INTEGER

New constraints indicate that the number of investments made by retailers is limited by their budget (20), the number of funds received by a cooperative should be distributed between the farms of such cooperative (21). Each fund increases the farm skill level in one level (22). Finally, the allocation of funds to farms is made in a way directly proportional to the area of the farm (23). Since $I n v_{i}$ is an integer variable, an 0.5 is added to (23) to round the obtained continuous value to the closer integer (and not the immediately inferior one).

Scenario B2. It allocates funds to farms in an inversely proportional way to the proportion of $1^{\text {st }}$ quality products obtained by farms (the lower the proportion of $1^{\text {st }}$ quality products, more funds) and is formulated as follows.

$\max Z_{B}$

Subject to:

(2) - (15), (20)-(22), (24)

$I n v_{i} \leq \sum_{j \in F C_{i}} \sum_{k} \frac{F J_{j k} \cdot \frac{1}{g_{i}}}{\frac{1}{\sum_{i_{2} \in I J_{j}} g_{i_{2}}}}+0.5 \quad \forall i$

The model for Scenario B2 is formulated similarly to the Scenario B1 model by changing the way of allocating funds to farms. In this case, the number of funds received by each farm of a cooperative is inversely proportional to the initial proportion of $1^{\text {st }}$ 
Model to Improve $1^{\text {st }}$ Quality Agricultural Production through Collaboration Program 8

quality product obtained from harvest. In other words, more funds are allocated to farms with lower initial proportion of $1^{\text {st }}$ quality product (25).

\subsection{Scenarios C: Investments to Cooperatives - Objectives Criteria}

In Scenarios C, retailers invest on cooperatives who share such funds among farms that compose them by optimizing more than one SC objective. A global objective is created by combining the objectives by means of the weighted sum method [16].

Scenario C1. It Scenario C1 maximizes the profits for the $\mathrm{SC}\left(Z_{B}\right)(19)$ and minimizes the economic unfairness among farmers $\left(Z_{u}\right)(26)$. Therefore, this model decides the distribution of funds among farmers while finding a trade-off between the supply chain profits and the unfairness in the distribution of farmers' incomes.

The economic unfairness is calculated as the absolute difference between the incomes per hectare of each farm and the mean income per hectare for all farms belonging to the SC (27). So, the lowest unfairness is, the most equitable will be the share of incomes among farms. To solve the non-linearity of (27), it is transformed into linear equations (28)-(30).

$$
\begin{aligned}
& \max Z=w_{1} \cdot \frac{Z_{B}}{Z_{B_{\max }}}-w_{2} \cdot \frac{Z_{u}}{Z_{u \max }} \\
& Z_{u}=\sum_{i}\left|\frac{\sum_{j \in I J_{i}} \sum_{v} \sum_{c} \sum_{t} Q J_{i j}^{v c t} \cdot s p_{j}^{v c t}}{a_{i}}-\sum_{i^{\prime}} \frac{\sum_{j \in I J_{i^{\prime}}} \sum_{v} \sum_{c} \sum_{t} Q J_{i^{\prime} j}^{v c t} \cdot s p_{j}^{v c t}}{a_{i}}\right| \\
& Z_{u}=\sum_{i} D_{i} \\
& D_{i} \geq \frac{\sum_{j \in I J_{i}} \sum_{v} \sum_{c} \sum_{t} Q J_{i j}^{v c t} \cdot s p_{j}^{v c t}}{a_{i}}-\sum_{i^{\prime}} \frac{\sum_{j \in I J_{i^{\prime}}} \sum_{v} \sum_{c} \sum_{t} Q J_{i^{\prime} j}^{v c t} \cdot s p_{j}^{v c t}}{a_{i}} \quad \forall i \\
& D_{i} \geq \sum_{i^{\prime}} \frac{\sum_{j \in I J_{i^{\prime}}} \sum_{v} \sum_{c} \sum_{t} Q J_{i^{\prime} j}^{v c t} \cdot s p_{j}^{v c t}}{a_{i}}-\frac{\sum_{j \in I J_{i}} \sum_{v} \sum_{c} \sum_{t} Q J_{i j}^{v c t} \cdot s p_{j}^{v c t}}{a_{i}} \quad \forall i \\
& \text { Subject to: } \\
& \text { (2) - (15), (20)-(22), (24) }
\end{aligned}
$$

Scenario C2. It maximizes the profits for the SC $\left(Z_{B}\right)(19)$ and minimizes the unfairness in the distribution of funds to farms $\left(Z_{I}\right)$ (31). Therefore, the model decides the distribution of funds among farmers while finding a trade-off between the supply chain profits and the unfairness in the funds' distribution.

The unfairness objective is calculated as the absolute difference between the number of funds received per farm and the funds received by all farms of the SC (32). To solve the non-linearity of (32), it is transformed into (33)-(35).

$$
\begin{aligned}
& \max Z=w_{1} \cdot \frac{Z_{B}}{Z_{B_{\max }}}-w_{2} \cdot \frac{Z_{I}}{Z_{I \max }} \\
& Z_{I}=\sum_{i}\left|I n v_{i}-\frac{\sum_{i^{\prime}} \operatorname{Inv_{i^{\prime }}} \mid}{I}\right| \\
& Z_{I}=\sum_{i} X_{i}
\end{aligned}
$$




\section{Implementation and Evaluation of Results}

The proposed models were implemented in the optimization software MPL ${ }^{\circledR}$ 5.0.6.114 and solved with the solver Gurobi ${ }^{\mathrm{TM}}$ 8.1.1. Microsoft Access Databases were used to import input data and to collect the obtained values for decision variables. The computer used to solve the model had an Intel ${ }^{\circledR}$ Xeon ${ }^{\circledR}$ CPU E5-2640 v2 with two $2.00 \mathrm{GHz}$ processors, with an installed memory RAM of $32.0 \mathrm{~GB}$ and a 64-bits operating system.

Data used to solve the models was extracted from [3] in which a 120 daily periods horizon (4 months) was considered with some modifications. Demand data is modified by multiplying it by a random value between 80 and $120 \%$ to create an imbalance between supply and demand. In addition, it is considered that $80 \%$ of demand is for $1^{\text {st }}$ quality vegetables while the rest represents the demand for $2^{\text {nd }}$ quality vegetables. It is also considered that vegetables have limited shelf-life since $1^{\text {st }}$ quality products become $2^{\text {nd }}$ quality in one period, and products of $2^{\text {nd }}$ quality become uneatable in one period.

Four evaluation parameters aligned to the three aspects of sustainability are defined to compare results obtained by the proposed scenarios and a scenario not considering the CP (No CP scenario): i) SC profits (economic), ii) proportion of harvest wasted (environmental), iii) unfairness in terms of incomes per hectare perceived by farms (social), and iv) unfairness in the allocation of funds to farms (social). The percentage of unmet demand and the total harvest for both qualities are also analyzed. The results obtained for proposed scenarios are shown in Fig. 2.

The Scenario No CP obtains the worst SC profits and the highest $2^{\text {nd }}$ quality products waste and $1^{\text {st }}$ quality products unmet demand. This means that imbalances between supply and demand, produce oversupply of $2^{\text {nd }}$ quality products and undersupply of $1^{\text {st }}$ quality products. All these indicators are highly improved when considering the CP.

Scenario A is considered as the benchmark for the SC as it obtains the best values for the SC profit, the proportion of harvest wasted, and the percentage of unmet demand for $1^{\text {st }}$ quality vegetables. However, it leads to the highest unmet demand for $2^{\text {nd }}$ quality products and to high unfairness in terms of income per hectare and distribution of funds.

Scenarios considering the business model where cooperatives act as intermediaries deciding how to distribute funds among farms (B1, B2, C1, C2), worsen the SC profits in Scenario A by 16-19\%. However, all of them triplicate the SC profits obtained when no considering the CP. In addition, these scenarios are fairer in terms of incomes and number of funds received by farms. This feeling of justice makes farms more willing to collaborate with the rest of actors of the SC.

It is remarkable that by considering objectives related to the unfairness perception by farms (Scenarios C1 and C2), the unfairness indicators can be highly reduced while the rest of indicators remain with similar results. These scenarios could be then used by 
cooperatives in cases in which farmers are very reluctant to collaborate and participate in a centralized decision-making approach.

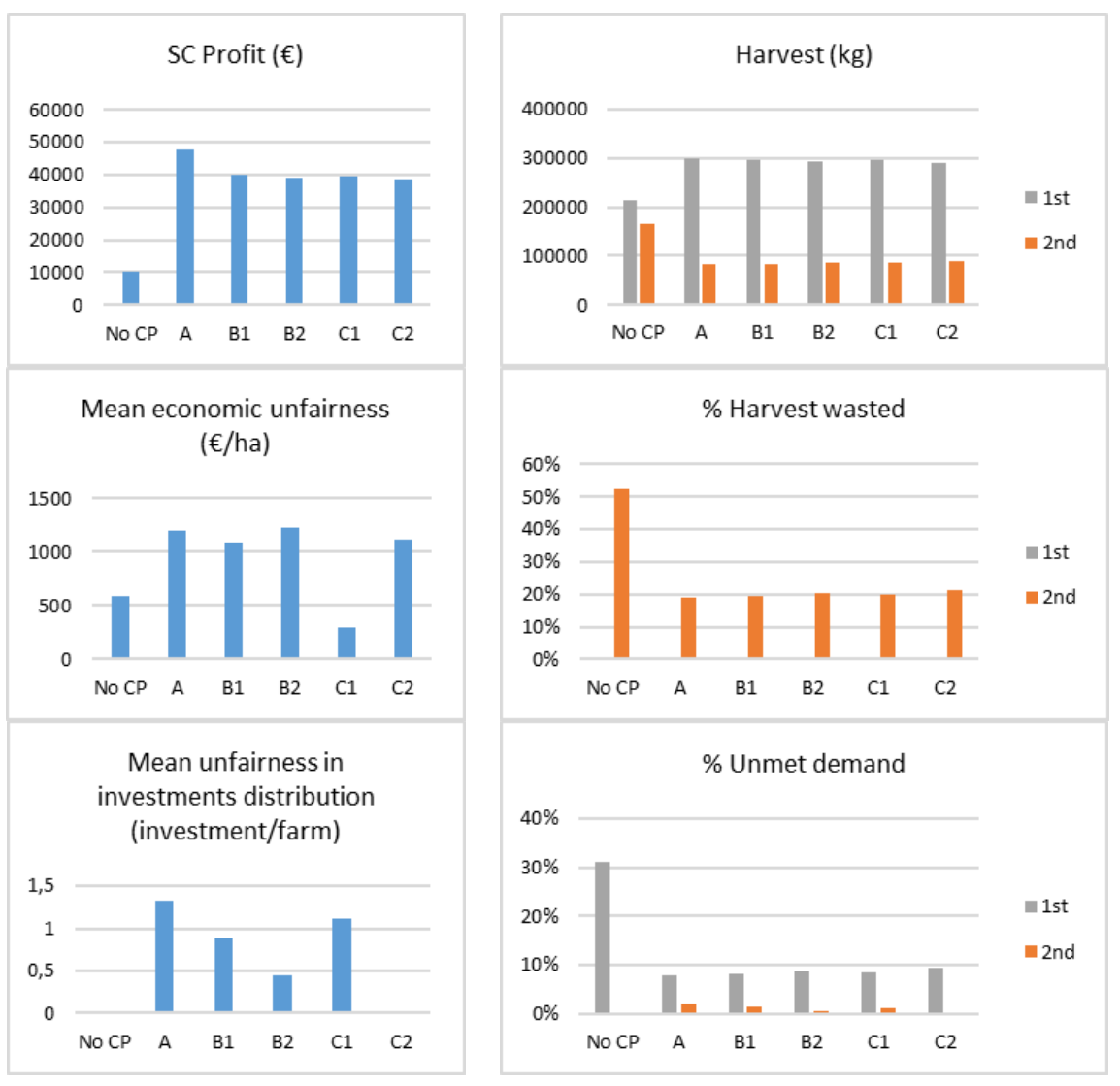

Fig. 2. Evaluation of Scenarios

The resolution time as well as the number of variables and constraints of solved models are displayed in Table 2 showing that proposed models solve immediately for the considered instance of data, and the size of the problem increases when investing in the cooperatives and when considering multiple objectives.

Table 3. Computational efficiency

\begin{tabular}{llllll}
\hline Scenario & Resolution time & Total variables & Continuous variables & Integer variables & Constraints \\
\hline A & 0.5 seconds & 10,578 & 10,560 & 18 & 9,499 \\
B1 & 0.4 seconds & 10,581 & 10,560 & 21 & 9,511 \\
B2 & 0.6 seconds & 10,581 & 10,560 & 21 & 9,511 \\
C1 & 1.3 seconds & 10,600 & 10,579 & 21 & 9,530 \\
C2 & 0.5 seconds & 10,600 & 10,560 & 40 & 9,530 \\
\hline
\end{tabular}


Model to Improve $1^{\text {st }}$ Quality Agricultural Production through Collaboration Program 11

\section{Conclusions}

This paper proposes five optimization models considering different ways used by cooperatives to share funds among farms in a new business model. These funds are used by farms to improve their skill level, increasing the proportion of $1^{\text {st }}$ quality products to be obtained from harvest. Results are analysed in terms of SC profit, percentage of harvest per quality, percentage of harvest wasted, percentage of unmet demand, economic unfairness among farms, and unfairness in the funds distribution. The best SC profit is obtained when retailers directly invest on farms (Scenario A) so it can be used as the SC benchmark. Although scenarios related to the new business model obtain profits $16-19 \%$ fewer than benchmark, all of them show similar results for the percentage of harvest per quality, waste and unmet demand. However, implementing the CP triples the SC profits obtained when the CP is not considered in all scenarios. The unfairness perception among farms is highly decreased in these scenarios (up to $75 \%$ for the economic unfairness and $100 \%$ for the unfairness in funds), making farms more willing to collaborate and participate in centralized decision-making processes.

Therefore, more effort is needed to find solutions with profits similar to the benchmark while reducing the unfairness among farms. For that, more collaboration mechanisms to share investments could be defined and tested in future proposals. In addition, the Nash theory could be used to share the incomes among farms once benchmark profits are obtained. Another future research line could be to ask real farms to rank the obtained solutions for defined scenarios and to collaboratively select the solution to be finally implemented in the agri-food SC by using a group decision support system. This study could also be extended by considering the uncertain and fuzzy nature of the models' parameters. With this, the impact of such uncertainty on the proposed ways to allocate investments to farms could be analyzed.

Acknowledgments. The authors acknowledge the partial support of Project 691249, "RUC-APS: Enhancing and implementing Knowledge based ICT solutions within high Risk and Uncertain Conditions for Agriculture Production Systems", funded by the EU under its funding scheme H2020-MCSA-RISE-2015.

\section{References}

1. S. Azevedo, M. Silva, J. Matias, G. Dias, The Influence of Collaboration Initiatives on the Sustainability of the Cashew Supply Chain, Sustainability. 10 (2018) 2075. doi:10.3390/su10062075.

2. FAO, The future of food and agriculture - Trends and challenges, Rome, 2017.

3. A. Esteso, M. del Mar E. Alemany, Á. Ortiz, C. Guyon, A Collaborative Model to Improve Farmers' Skill Level by Investments in an Uncertain Context, in: IFIP Adv. Inf. Commun. Technol., 2018: pp. 590-598. doi:10.1007/978-3-319-99127-6 51.

4. W. Sutopo, M. Hisjam, Yuniaristanto, An Agri-food Supply Chain Model to Empower Farmers for Supplying Deteriorated Product to Modern Retailer, in: G.-C. Yang, S.-I. Ao, X. Huang, O. Castillo (Eds.), IAENG Trans. Eng. Technol. Spec. Issue Int. MultiConference Eng. Comput. Sci. 2012, Springer Netherlands, Dordrecht, 2013: pp. 189-202. doi:10.1007/97894-007-5651-9 14. 
Model to Improve $1^{\text {st }}$ Quality Agricultural Production through Collaboration Program 12

5. W. Sutopo, M. Hisjam, Yuniaristanto, B. Kurniawan, A Goal Programming Approach for Assessing the Financial Risk of Corporate Social Responsibility Programs in Agri-food Supply Chain Network, Proc. World Congr. Eng. 2013. I (2013) 732-736.

6. W. Sutopo, M. Hisjam, Yuniaristanto, An Agri-food Supply Chain Model for Cultivating the Capabilities of Farmers Accessing Market Using Social Responsibility Program, Int. Sch. Sci. Res. Innov. 5 (2011) 1588-1592.

7. W. Sutopo, M. Hisjam, Yuniaristanto, An Agri-Food Supply Chain Model To Enhance the Business Skills of Small-Scale Farmers Using Corporate Social Responsibility, Makara, Teknol. 16 (2012) 43-50.

8. W. Sutopo, M. Hisjam, Yuniaristanto, Developing an Agri-Food Supply Chain Application for Determining the Priority of CSR Program to Empower Farmers as a Qualified Supplier of Modern Retailer, 2013 World Congr. Eng. Comput. Sci. WCECS 2013. 2 (2013) 1180-1184.

9. R.S. Wahyudin, W. Sutopo, M. Hisjam, Yuniaristanto, B. Kurniawan, An Agri-food Supply Chain Model for Cultivating the Capabilities of Farmers in Accessing Capital Using Corporate Social Responsibility Program, Proc. Int. MultiConference Eng. Comput. Sci. II (2015) $877-$ 882.

10.L.M. Plà, D.L. Sandars, A.J. Higgins, A perspective on operational research prospects for agriculture, J. Oper. Res. Soc. 65 (2014) 1078-1089. doi:10.1057/jors.2013.45.

11.Y. Handayati, T.M. Simatupang, T. Perdana, Agri-food supply chain coordination: the stateof-the-art and recent developments, Logist. Res. 8 (2015) 1-15. doi:10.1007/s12159-015$0125-4$.

12.I. Moon, Y.J. Jeong, S. Saha, Investment and coordination decisions in a supply chain of fresh agricultural products, Oper. Res. (2018) 1-25. doi:10.1007/s12351-018-0411-4.

13.H. Stadtler, A framework for collaborative planning and state-of-the-art, OR Spectr. 31 (2009) 5-30. doi:10.1007/s00291-007-0104-5.

14.J.E. Hernández, A.C. Lyons, R. Poler, J. Mula, R. Goncalves, A reference architecture for the collaborative planning modelling process in multi-tier supply chain networks: a Zachmanbased approach, Prod. Plan. Control. 25 (2014) 1118-1134 doi:10.1080/09537287.2013.808842.

15.A. Esteso, M.M.E. Alemany, A. Ortiz, Conceptual framework for managing uncertainty in a collaborative agri-food supply chain context, 2017. doi:10.1007/978-3-319-65151-4_64.

16.A. Esteso, M.M.E. Alemany, Á. Ortiz, D. Peidro, A multi-objective model for inventory and planned production reassignment to committed orders with homogeneity requirements, Comput. Ind. Eng. 124 (2018) 180-194. doi:10.1016/j.cie.2018.07.025 